\title{
CORRESPONDENCE
}

\section{Crisis resolution/home treatment teams for people with learning disabilities}

Bradley \& Lofchy (2005) should be commended for their comprehensive summary of the assessment and management of people with learning disabilities presenting in a crisis to an A\&E department. As the authors rightly point out, the whole process of attending A\&E can be especially frightening and anxiety-provoking for learning-disabled people. This may further exacerbate the existing crisis of agitation or aggression, possibly leading to physical violence.

In the UK, services for people with learning disabilities are most commonly provided by community learning disability teams (Bouras \& Holt, 2004). In Birmingham, where I have been training as a specialist registrar for the past 3 years, a crisis resolution/home treatment (CRHT) team provides outof-hours support for learning-disabled people in crisis. The team usually consists of two community learning disability nurses. They can be contacted through NHS Direct and receive out-of-hours referrals from a number of sources, including families, care homes and general practitioners. The team manages the crisis in the community (at the patient's place of residence) and has direct access to the on-call consultant learning disability psychiatrist for management advice or a joint assessment. Such management has averted a number of individuals from the $A \& E$ department or admission to an in-patient unit.

If the individual concerned responds to neither nonpharmacological nor pharmacological (excluding rapid tranquillisation, which is only done in an acute psychiatric unit) interventions, admission to an inpatient unit is considered either informally or under the Mental Health Act 1983. If an individual is in significant immediate danger of harming him- or herself or others, the police are called to take the person into custody, where the crisis team and consultant psychiatrist jointly intervene, as described above.

Although we do not yet have a CRHT team specifically for people with learning disabilities that operates during working hours, we are in the process of developing one.

Bouras, N. \& Holt, G. (2004) Mental health services for adults with learning disabilities. British Journal of Psychiatry, 184, 291-292.

Bradley, E. \& Lofchy, J. (2005) Learning disability in the accident and emergency department. Advances in Psychiatric Treatment, 11, 45-57.

C. Feroz-Nainar Acting Consultant in Learning Disability Psychiatry, South Birmingham Primary Care Trust, UK. Email: doctorferoz@yahoo.co.uk

\section{A physical lesson for the clinicians?}

In 2002, a colleague (P. Jeyapaul) and I conducted an audit on physical examination in psychiatric practice while we were working as senior house officers in a teaching hospital. The standard for the audit was that every patient should have received a basic physical examination within $72 \mathrm{~h}$ of admission. Of the 78 patients included in the audit, $17(22 \%)$ received a complete examination and $27(35 \%)$ were not examined at all. Of those who were not examined, 9 did not consent and 2 were agitated; no reason was given for the failure to examine the others. The remaining $34(43 \%)$ received an incomplete examination, the most neglected area being the central nervous system. Out of the 78 patients, the records of only 1 mentioned that the skin was examined for evidence of self-harm and substance misuse.

Garden's (2005) article rightly stresses the need to keep up to date with these basic skills and the different areas of focus in the physical examination and their relevance to psychiatric disorders.

Garden, G. (2005) Physical examination in psychiatric practice. Advances in Psychiatric Treatment, 11, 142-149.

Pavan Chahl Staff Grade Psychiatrist, Hellesdon Hospital Norwich, UK. E-mail: pavandridoc@rediffmail.com

\section{... and for their educators?}

In response to the article by Dr Gill Garden (Garden, 2005) on physical examination in psychiatric practice, I would like to highlight some of the problems that trainees in psychiatry frequently encounter.

I certainly applaud the Royal College of Psychiatrists' increased awareness of physical illnesses and the importance of detecting them, but I fear that the level of teaching that juniors receive for this is extremely poor. Indeed, having come through a large SHO rotational scheme, I cannot recall a single lecture that was devoted to carrying out a physical examination and yet this is now an essential component of the OSCE in the MRCPsych Part I exam. Even in Part II, as many marks are set aside for the physical examination as for the mental state examination.

In a field such as rehabilitation psychiatry, patients' physical problems are even more important because individuals are often on high doses of medication (possibly with polypharmacy) and are usually older and less physically active. Fortunately at St Michael's Hospital in Warwick, a local GP has 